we strongly recommend a second TNFi, IL-17i, IL-23i and JAKi. Certainty of evidence (GRADE) and recommendations for peripheral arthritis domain of PsA for different population groups are shown in Table 1. While the evidence supporting non-pharmacological treatments was low, we derived the recommendations from clinician/PRP expert opinion, included advocating an increase in physical activity, smoking cessation and a healthy diet to control weight gain.

Conclusion: Evidence supporting drug treatment for the peripheral arthritis domain of PsA was compiled, providing required information for the revised GRAPPA treatment recommendations. Further work seeking agreement from a broader group of stakeholders is in progress.

Table 1. Certainty of evidence (GRADE) and Recommendation for peripheral arthritis of PsA

\begin{tabular}{|c|c|c|c|c|c|c|}
\hline \multirow[b]{2}{*}{$\begin{array}{l}\text { Drug } \\
\text { class }\end{array}$} & \multicolumn{2}{|c|}{ Treatment naive } & \multicolumn{2}{|c|}{$\begin{array}{l}\text { csDMARD inadequate } \\
\text { response }\end{array}$} & \multicolumn{2}{|c|}{$\begin{array}{l}\text { bDMARD inadequate } \\
\text { response }\end{array}$} \\
\hline & $\begin{array}{l}\text { evidence } \\
\text { (GRADE) }\end{array}$ & $\begin{array}{l}\text { Recom- } \\
\text { mendation }\end{array}$ & $\begin{array}{l}\text { evidence } \\
\text { (GRADE) }\end{array}$ & $\begin{array}{l}\text { Recom- } \\
\text { mendation }\end{array}$ & $\begin{array}{l}\text { evidence } \\
\text { (GRADE) }\end{array}$ & $\begin{array}{l}\text { Recom- } \\
\text { mendation }\end{array}$ \\
\hline PDE-4i & $\begin{array}{l}\text { Mod to } \\
\text { high }\end{array}$ & $\begin{array}{c}\text { Strong for } \\
\text { (mild/ mod } \\
\text { disease) } \\
\text { Conditional for } \\
\text { (severe disease) }\end{array}$ & $\begin{array}{l}\text { Mod to } \\
\text { High }\end{array}$ & Strong for & $\begin{array}{c}\text { bDMARD } \\
\text { exp: } \\
\text { Mod } \\
\text { bDMARD } \\
\text { IR: } \\
\text { Mod } \\
\text { (NS) }\end{array}$ & $\begin{array}{l}\text { Conditional for } \\
\text { (bDMARD } \\
\text { exp) } \\
\text { Conditional } \\
\text { against } \\
\text { (bDMARD IR) }\end{array}$ \\
\hline TNFi & High & Strong for & High & Strong for & Mod & $\begin{array}{l}\text { Strong for } \\
\text { a } 2^{\text {nd }} T N F i\end{array}$ \\
\hline Vs. MTX & High & $\begin{array}{l}\text { Strong for TNFi } \\
\text { as } 1 \text { st line for } \\
\text { severe disease }\end{array}$ & - & - & - & - \\
\hline IL-17i & High & Strong for & High & Strong for & $\begin{array}{l}\text { Mod to } \\
\text { high }\end{array}$ & Strong for \\
\hline IL-12/23i & $\begin{array}{l}\text { i Mod to } \\
\text { high }\end{array}$ & Strong for & $\begin{array}{l}\text { Mod to } \\
\text { High }\end{array}$ & Strong for & Low & $\begin{array}{l}\text { Conditional } \\
\text { for }\end{array}$ \\
\hline IL-23i & High & Strong for & High & Strong for & Mod & Strong for \\
\hline JAKi & $\operatorname{Mod}^{*}$ & Strong for & High & Strong for & $\begin{array}{r}\text { Mod to } \\
\text { High }\end{array}$ & Strong for \\
\hline CTLA4i & Very Low & Conditional for $^{\dagger}$ & Low & $\begin{array}{c}\text { Conditional } \\
\text { for }^{\dagger}\end{array}$ & Mod (NS) & $\begin{array}{l}\text { Conditional } \\
\text { for }^{\dagger}\end{array}$ \\
\hline $\begin{array}{l}\text { Dual } \\
\qquad \text { TNFi/ } \\
\text { IL17i }\end{array}$ & Moderate & NA $^{*}$ & Mod & NA $^{*}$ & NA & $N^{*}$ \\
\hline IL-6i & Very Low C & Fonditional against & $\begin{array}{r}\text { t Very low } \\
\text { to low }\end{array}$ & $\begin{array}{c}\text { Conditional } \\
\text { against }\end{array}$ & NA & $\begin{array}{l}\text { Conditional } \\
\text { against }\end{array}$ \\
\hline
\end{tabular}

NS: not statistically significant; ${ }^{*}$ included data from abstract; ${ }^{*}$ not making recommendation due to not approved and not available in market; ${ }^{\dagger}$ reserve for no alternatives. Mod: Moderate; exp: experienced; IR: inadequate response.

Acknowledgements: We are grateful to the contribution of our patient research partner, Rodrigo Firmino

Disclosure of Interests: None declared.

DOI: 10.1136/annrheumdis-2021-eular.900

\section{AB0532 MAINTENANCE OF RESPONSE THROUGH 5 YEARS OF CONTINUOUS GUSELKUMAB TREATMENT: RESULTS FROM THE PHASE-3 VOYAGE 1 TRIAL}

C. E. M. Griffiths ${ }^{1,2}$, K. Papp ${ }^{3,4}$, M. Song ${ }^{5}$, M. Miller ${ }^{5}$, Y. You ${ }^{6}$, Y. K. Shen ${ }^{6}$, A. Blauvelt'. ${ }^{1}$ NIHR Manchester Biomedical Research Centre, University of Manchester, Dermatology Centre, Manchester, United Kingdom; ${ }^{2}$ Salford Royal NHS Foundation Trust, Dermatology Department, Salford, United Kingdom; ${ }^{3}$ K. Papp Clinical Research, Department of Dermatology, Waterloo, Ontario, Canada; ${ }^{4}$ Probity Research Inc., Clinical Research, Waterloo, Ontario, Canada; Janssen Research \& Development, LLC, Department of Immunology, Spring House, Pennsylvania, United States of America; ${ }^{6}$ Janssen Research \& Development, LLC, Clinical Biostats, Spring House, Pennsylvania, United States of America; ${ }^{7}$ Oregon Medical Research Center, Department of Dermatology, Portland, Oregon, United States of America

Background: VOYAGE 1, a phase-3, double-blinded, placebo- and active comparator-controlled study evaluated the efficacy and safety of guselkumab (GUS; a fully human anti-interleukin-23 monoclonal antibody) in patients with moderate-to-severe plaque psoriasis. ${ }^{1,2,3}$

Objectives: To assess the efficacy and safety through 5 years of continuous GUS treatment.

Methods: In VOYAGE 1, patients were randomized to GUS $100 \mathrm{mg}$ at Weeks $0,4,12$, then every 8 weeks (q8w); placebo at Weeks $0,4,12$ followed by GUS $100 \mathrm{mg}$ at Weeks 16, 20 then q8w; or adalimumab $80 \mathrm{mg}$ at Week $0,40 \mathrm{mg}$ at
Week 1, then $40 \mathrm{mg}$ every 2 weeks (q2w) through Week 47. At Week 52, all patients continued open-label GUS through Week 252. Efficacy assessments included proportions of patients achieving $\geq 90 \%$ or $100 \%$ improvement in Psoriasis Area and Severity Index (PASI 90, PASI 100), and Investigator's Global Assessment scores of cleared/minimal or cleared (IGA 0/1, IGA 0). Three statistical methods were used to analyze efficacy: prespecified Treatment Failure Rules (TFR), Nonresponder Imputation (NRI), and As Observed (OBS). For TFR analyses, patients who discontinued study agent due to lack of efficacy, worsening of psoriasis, or use of a protocol-prohibited psoriasis treatment were considered nonresponders. For NRI analyses, patients with missing efficacy data (regardless of the reason) after application of TFR were counted as nonresponders. For OBS analyses, missing data were not imputed. Safety was assessed through Week 264.

Results: Among a total of 494 patients randomized to GUS at Week $0(\mathrm{~N}=329)$ and placebo patients who crossed over to GUS at Week $16(\mathrm{~N}=165), 76.9 \%$ (380/494) continued study agent through Week 252. PASI 90 responses were well-maintained with up to 5 years of continuous GUS use. At Week 52, PASI 90 response rates were $79.7 \%, 75.5 \%$, and $80.6 \%$ based on TFR, NRI, and OBS analyses, respectively; corresponding rates at Week 252 were $84.1 \%, 66.6 \%$, and $86.6 \%$. Likewise, PASI 100, IGA 0/1, and IGA 0 responses were maintained from Week 52 through Week 252 (Table 1). Efficacy was also maintained through Week 252 in patients randomized to GUS at Week $0(\mathrm{~N}=329)$. Through the end of the study for all patients (GUS group and adalimumab $\rightarrow$ GUS crossover group; $\mathrm{N}=774$ ), the proportion of patients reporting at least one adverse event $(A E)$, serious $\mathrm{AE}$, or discontinuation due to $\mathrm{AEs}$ were $87.7 \%, 16.4 \%$, and $6.1 \%$, respectively. Rates of AEs of interest through Week 264 were as follows: serious infections (2.8\%), malignancies (nonmelanoma skin cancer [1.7\%]; cancer other than nonmelanoma skin cancer [2.3\%]), major adverse cardiovascular events (1.0\%), and suicidal ideation and behavior $(0.6 \%)$.

Conclusion: High efficacy response rates were maintained (regardless of the method used to analyze data) and no new safety concerns were identified through 5 years of continuous GUS treatment in VOYAGE 1.

\section{EFENCES:}

[1] Blauvelt A et al. J Am Acad Derm 2017;76:405-417

[2] Griffiths CEM et al. J Drugs Dermatol 2018;17:826-832

[3] Griffiths CEM et al. J Dermatol Treat 2020;13:1-9

Table 1. Proportion of Patients in the GUS Group ${ }^{a}$ Achieving Clinical Responses by Analysis Type at Week 52 and Week 252

\begin{tabular}{lcccccc}
\hline & \multicolumn{3}{c}{ Week 52 } & \multicolumn{3}{c}{ Week 252 } \\
\hline & $\begin{array}{c}\text { TFR } \\
(\mathrm{N}=468) \\
(\%)\end{array}$ & $\begin{array}{c}\text { NRI } \\
(\mathrm{N}=494) \\
(\%)\end{array}$ & $\begin{array}{c}\text { OBS }(\mathrm{N}=463) \\
(\%)\end{array}$ & $\begin{array}{c}\text { TFR } \\
(\mathrm{N}=391) \\
(\%)\end{array}$ & $\begin{array}{c}\text { NRI } \\
(\mathrm{N}=494) \\
(\%)\end{array}$ & $\begin{array}{c}\text { OBS } \\
(\mathrm{N}=380) \\
(\%)\end{array}$ \\
\hline PASI 90 & 77.9 & 75.5 & 80.6 & 84.1 & 66.6 & 86.6 \\
PASI 100 & 49.7 & 46.6 & 49.7 & 52.7 & 41.7 & 54.2 \\
IGA 0 & 84.6 & 80.2 & 85.5 & 82.4 & 65.2 & 84.7 \\
IGA 0 & 53.3 & 50.8 & 54.2 & 54.7 & 43.3 & 56.3
\end{tabular}

GUS, guselkumab; IGA, Investigator's Global Assessment; NRI, nonresponder imputation method; OBS, As Observed method; PASI, Psoriasis Area and Severity Index; TFR, treatment failure rules method ${ }^{\mathrm{a}}$ Includes patients randomized to GUS and placebo patients who crossed over to GUS at Week 16

Disclosure of Interests: Christopher E.M. Griffiths Speakers bureau: AbbVie, Eli Lilly, Janssen, Leo, Novartis, Pfizer, Sandoz, and Sun Pharma, Consultant of AbbVie, Eli Lilly, Janssen, Leo, Novartis, Pfizer, Sandoz, and Sun Pharma, Grant/ research support from: AbbVie, Eli Lilly, Janssen, Leo, Novartis, Pfizer, Sandoz, and Sun Pharma, Kim Papp Speakers bureau: AbbVie, Amgen, Astellas, Baxalta Baxter, Boehringer Ingelheim, Bristol-Myers Squibb, Celgene, Centocor, Dermira, Eli Lilly, Forward Pharma, Galderma, Genentech, GlaxoSmithKline, Janssen, Kyowa-Hakko Kirin, Leo Pharma, Medlmmune, Merck-Serono, Merck Sharp \& Dohme, Novartis, Pfizer, Regeneron, Roche, Sanofi-Genzyme, Stiefel, Sun Pharma, Takeda, UCB, and Valeant, Consultant of: AbbVie, Amgen, Astellas Baxalta, Baxter, Boehringer Ingelheim, Bristol-Myers Squibb, Celgene, Centocor, Dermira, Eli Lilly, Forward Pharma, Galderma, Genentech, GlaxoSmithKline Janssen, Kyowa-Hakko Kirin, Leo Pharma, Medlmmune, Merck-Serono, Merck Sharp \& Dohme, Novartis, Pfizer, Regeneron, Roche, Sanofi-Genzyme, Stiefel Sun Pharma, Takeda, UCB, and Valeant, Grant/research support from: AbbVie, Amgen, Astellas, Baxalta, Boehringer Ingelheim, Bristol-Myers Squibb, Celgene, Centocor, Dermira, Eli Lilly, Galderma, Genentech, GlaxoSmithKline, Janssen, Kyowa-Hakko Kirin, Leo Pharma, Medlmmune, Merck-Serono, Merck Sharp \& Dohme, Novartis, Pfizer, Regeneron, Roche, Sanofi-Genzyme, Stiefel, Takeda, UCB, and Valeant, Michael Song Shareholder of: Johnson and Johnson, Employee of: Janssen Research \& Development, LLC, Megan Miller Shareholder of: Johnson and Johnson, Employee of: Janssen Research \& Development, LLC 
Yin You Shareholder of: Johnson and Johnson, Employee of: Janssen Research \& Development, LLC, Yaung-Kaung Shen Shareholder of: Johnson and Johnson, Employee of: Janssen Research \& Development, LLC, Andrew Blauvelt Speakers bureau: AbbVie, Consultant of: AbbVie, Aclaris, Almirall, Arena, Athenex, Boehringer Ingelheim, Bristol-Myers Squibb, Dermavant, Dermira, Eli Lilly, FLX Bio, Forte, Galderma, Janssen, Leo, Novartis, Ortho, Pfizer, Regeneron, Sandoz, Sanofi Genzyme, Sun Pharma, and UCB Pharma DOI: 10.1136/annrheumdis-2021-eular.960

\section{AB0533 COMBINATION OF METHOTREXATE AND LEFLUNOMIDE IS SAFE AND HAS GOOD DRUG RETENTION AMONG PATIENTS WITH PSORIATIC ARTHRITIS}

M. Haroon ${ }^{1}$, S. Batool ${ }^{2}$, S. Asif ${ }^{2}$, F. Hashmi ${ }^{2}$, S. Ullah ${ }^{2}{ }^{1}$ Fatima Memorial Hospital \& FMH College of Medicine and Dentistry, Department of Rheumatology, Lahore, Pakistan; ${ }^{2}$ Fatima Memorial Hospital \& FMH College of Medicine and Dentistry, Department of Rheumatology, Lahore, Pakistan

Background: Among patients with psoriatic arthritis (PsA), there remains a considerable confusion regarding the effectiveness of conventional synthetic DMARDs (csDMARDs), especially methotrexate (MTX). The availability of biologic DMARDs and targeted synthetic DMARDs have revolutionised the management of psoriatic disease; however, it comes with a significant cost burden. We believe that combination of DMARDs, especially combining MTX and Leflunomide (LEF) provides a valuable low-cost treatment option for patients with PsA after failure of MTX monotherapy. Hence, in our practice, we are inclined to use combination of potent DMARDs after MTX failure, prior to considering biologic therapies. Little is known about the combination use of LEF and MTX in PSA, especially in the context of drug retention time and tolerability.

Objectives: We aimed to review our PsA cohort data especially examining the drug retention of first-line csDMARD monotherapy and combination csDMARDs.

Methods: In our centre, MTX is a preferred first line csDMARD, unless contraindicated, and patients are followed up with a protocol on 4-6 weekly basis unless complete remission is achieved. MTX if needed is escalated to the maximum tolerated dose (up to $25 \mathrm{mg} /$ week), and if PsA is still active then preferably LEF is added (usual starting dose for add-on therapy is $10 \mathrm{mg}$ a day and if needed escalated to $20 \mathrm{mg}$ a day, without any loading dose). Other csDMARDs, such as sulphasalazine are used, if needed. For this study, after written-informed consent, only those adult patients were included who had a follow up of at least 6 months with our rheumatology services, and were fulfilling CASPAR criteria. Moreover, only patients who were DMARD-naïve (no prior DMARD therapy for any cause, including psoriasis), and initiated DMARD as monotherapy after 1 April 2018 were included. If any patient had already been on any DMARDs prior to attending our rheumatology services was excluded.

Results: A total of 81 PsA patients [mean age $45.6 \pm 6$ years; $52 \%$ male; mean PsA disease duration $=9 \pm 4$ years; $35 \%$ with dactylitis, $42 \%$ with enthesitis, $17 \%$ with sacroiliitis, median current PASI $=2.6$, median number of swollen joints $=8.0$, median number of tender joints $=11.0]$ fulfilled the inclusion and exclusion criteria. As regards first-line csDMARD monotherapy, $88 \%(n=71)$ of patients were commenced on MTX. In total, $79 \%$ ( $n=56$ out of 71 ) of patients who were started on MTX as their first-line csDMARD therapy failed this monotherapy during follow-up ( $51=$ ineffective, 5 =intolerance). After a median follow-up of 22 months, MTX median drug retention among all MTX monotherapy users ( $n=71$ ) was only 7 months (IQR 5-7); and among MTX failures $(n=56)$, MTX monotherapy median drug retention was 6.0 months (IQR 4-8). Eighty percent ( $n=45$ out of 56) of the MTX monotherapy failure cohort was started on combination therapy of MTX and LEF (combo MTX+LEF); among them, only 7 patients needed escalation of therapy to bDMARDs, and the rest are still using combo MTX+LEF. It was noted that to date median drug retention time of combo MTX+LEF has been 8 months (IQR 7-11), and $84 \%$ ( $n=38$ out of 45 ) of these patients are still using this combo therapy. Significantly more patients managed to continue the combo MTX+LEF therapy compared to MTX monotherapy $(84 \%$ vs. $21 \%, p<0.001)$

Conclusion: Among csDMARD naïve PsA patients, $79 \%$ of patients failed MTX monotherapy with median drug retention time of only 6 months. Combination of MTX and LEF was well tolerated and had good drug retention time, with $84 \%$ of patients having ongoing treatment to date. Our data provides initial evidence that MTX and LEF combination therapy could be an effective treatment option for PsA

Disclosure of Interests: Muhammad Haroon Speakers bureau: Roche, Novartis, Grant/research support from: Abbvie, Pfizer, Shabnam Batool: None declared., Sadia Asif: None declared., Farzana Hashmi: None declared., Saadat Ullah: None declared.

DOI: 10.1136/annrheumdis-2021-eular.978

\section{AB0534 \\ THE IMPACT OF AXIAL INVOLVEMENT ON ACR RESPONSE IN PATIENTS WITH PSORIATIC ARTHRITIS RESULTS OF SUBANALYSIS OF THE PATERA STUDY}

T. Korotaeva ${ }^{1}$, I. Gaydukova ${ }^{2}$, V. Mazurov ${ }^{2}$, A. Samtsov ${ }^{3}$, V. Khayrutdinov ${ }^{3}$, A. Bakulev ${ }^{4}$, A. Kundzer ${ }^{5}$, N. Soroka ${ }^{6}$, A. Eremeeva ${ }^{7}{ }^{1}$ Nasonova Research Institute of Rheumatology, Laboratory of Spondyloarthritides and Psoriatic Arthritis, Moscow, Russian Federation; ${ }^{2}$ Mechnikov North-Western State Medical University, Department of Therapy and Rheumatology of Temporary Disability and Medical Care Quality Expertise, St-Petersburg, Russian Federation; ${ }^{3}$ Kirov Military Medical Academy, Department of Skin and Veneral Diseases, St-Petersburg, Russian Federation; ${ }^{4}$ Razumovsky Saratov State Medical University, Department of Dermatovenereology and Cosmetology, Saratov, Russian Federation; ${ }^{5}$ Belarusian Medical Academy of Postgraduate Education, Department of Cardiology and Rheumatology, Minsk, Belarus; ${ }^{6}$ Belarusian State Medical University, Department of Internal Diseases №2, Minsk, Belarus; ${ }^{7}$ JSC BIOCAD, Clinical Development Department, St-Petersburg, Russian Federation

Background: Inflammatory back pain (IBP) is a common symptom of axial disease in patients with psoriatic arthritis (PsA). The reported prevalence of axial disease in patients with PsA is quite variable and must be taken into account while choosing treatment strategy. Netakimab (NTK) is an anti-interleukin-17A monoclonal antibody approved for psoriasis, ankylosing spondylitis, PsA in Russia and Belarus.

Objectives: A subanalysis was aimed to investigate the ACR (American College of Rheumatology) 20/50/70 response rate in PsA patients with/without the axial disease, defined by the presence of IBP according to self-reported ASAS IBP criteria, 2009 at baseline.

Methods: PATERA is an ongoing phase 3 international double-blind, placebo-controlled clinical study (NCT03598751). 194 adult patients with PsA (CASPAR criteria, 2006) with inadequate response to csDMARD or one TNFi, were randomly assigned to receive NTK $120 \mathrm{mg}$ or placebo at weeks $0,1,2,4,6,8,10,14,18,22$. The ACR response was calculated in NTK-treated patients with IBP $(\operatorname{IBP}(+))$ and NTK-treated patients without IBP (IBP(-)) according to self-reported ASAS IBP criteria, 2009. Patients with missing values for categorical variables were considered as non-responders in the analysis.

Results: 97 PsA patients (N=54 IBP(+), N=43 IBP(-)) received NTK. Both subpopulations were comparable in gender, age, and PsA activity at baseline. There were no significant differences in ACR20 achievement between the groups (Figure 1). The percentage of patients with ACR50 was significantly $(p<0.05)$ higher in the IBP(-) subpopulation at weeks 4-20 (data not shown), but not at week 24 with $63 \% \mathrm{IBP}(+)$ and $79 \% \mathrm{IBP}(-)$ responders $(\mathrm{p} \geq 0.05)$. Similarly, IBP(+) patients had a lower frequency of ACR70 response (Figure 1).

Conclusion: NTK is effective in PsA treatment irrespectively of the presence of axial disease. Both IBP(-) and IBP(+) subpopulations achieved ACR20/50/70 as well, however, the benefit in IBP(-) patients was more pronounced.

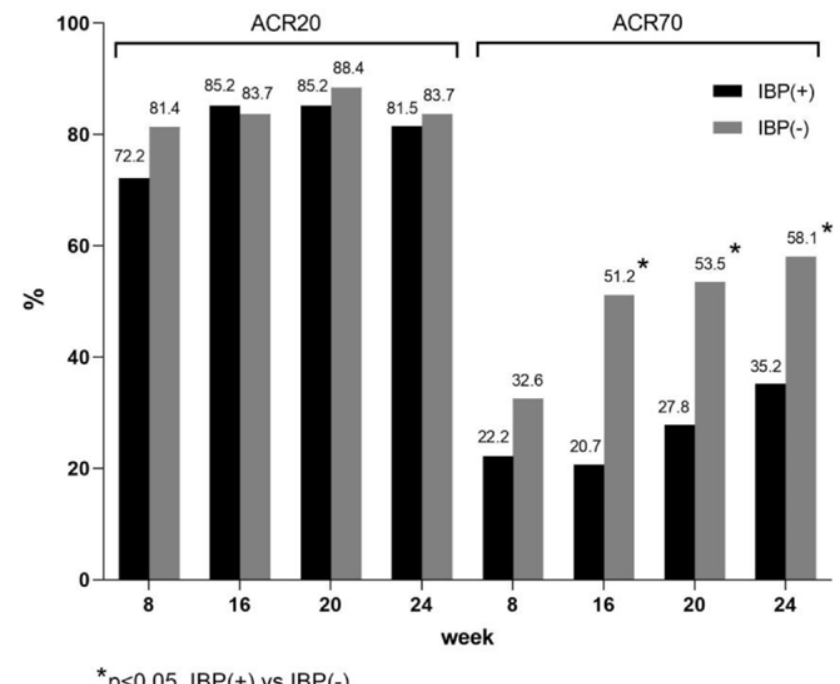

Figure $1 \mathrm{ACR}$ response rates

Acknowledgements: This study was sponsored by JSC BIOCAD.

Disclosure of Interests: Tatiana Korotaeva Speakers bureau: Abbvie, Biocad, Eli Lilly, Johnson \& Johnson, Janssen, Novartis, Pfizer, UCB, Inna Gaydukova 